\title{
Sparing effect of hemiplegia on tophaceous
} gout

\author{
JAMES J. GLYNN,* AND MACK L. CLAYTON $\dagger$
}

From the Departments of Orthopedic Surgery, University of California, San Francisco, and St. Joseph Hospital, Denver, Colorado

\begin{abstract}
Glynn, J. J., and Clayton, M. L. (1976). Annals of the Rheumatic Diseases, 35, 534-535. Sparing effect of hemiplegia on tophaceous gout. The sparing effect of hemiplegia on the development of tophaceous gout is described. The useless upper limb had no tophaceous deposits and the partially paralysed lower limb had only limited urate deposits. Disuse was presumably the major contributor to the limited deposition of urates on the paralysed side.
\end{abstract}

The sparing effect of hemiplegia on the development of various types of arthritis has been noted in the past (Coste and Forestier, 1935; Thompson and Bywaters, 1962; Courtright and Kuzell, 1965). We report a 57-year-old white man with tophaceous gout limited mainly to the limbs on one side. A stroke had paralysed his left arm and leg 10 years earlier, the subsequent gouty arthritis being restricted to the unparalysed right side.

\section{Case report}

A 57-year-old man was referred to us for operative evaluation of gouty tophaceous deposits of the dorsum of the right index, middle, and little fingers. 20 years earlier he had first experienced pain, swelling, and inflammation of the great toes of both feet. Over the next 10 years he had had two or three attacks of acute pain and swelling of the same joints. 10 years ago a right carotid artery occlusion had resulted in hemiparesis of the left side. Since then his left arm has been totally useless and his left leg has remained weak, but he has been able to walk without the use of a brace. The first recorded uric acid determination, done 10 years ago, was $8.8 \mathrm{mg} / 100 \mathrm{ml}$ $(0.52 \mathrm{mmol} / \mathrm{l})$.

For the past 4 years he has had frequent attacks of joint pain and swelling in both upper and lower limbs, but these acute gouty episodes have been restricted to the right side. Approximately 2 years ago he developed chronic gouty arthritis with joint pain and swelling lasting for weeks or months at a time. The more prolonged episodes of joint inflammation have been associated with the development of tophi of the right hand, elbow, knee, and foot. During this same 2-year period no nodules developed on the paralysed left arm; a sirgel small tophus, however, appeared in the left prepatedia region. At no time have any acute spells of gout occured on the paralysed left side.

Before the most recent examination he had bees treated with phenylbutazone (Butazolidin) with goof symptomatic results. However, he had not received ang uricosuric drugs or other therapy to control the hypere uricaemia. 2 months ago he was given allopurinof (Zyloprim, $300 \mathrm{mg}$ each morning) for the first time. A aunt has gout, and 20 years ago the patient had kidney stones.

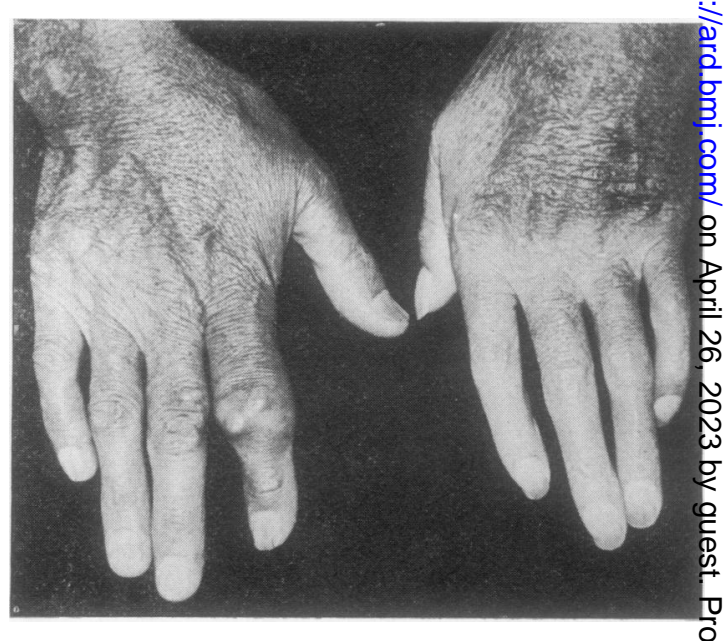

FIG. 1 Tophaceous deposits in unparalysed right hand 


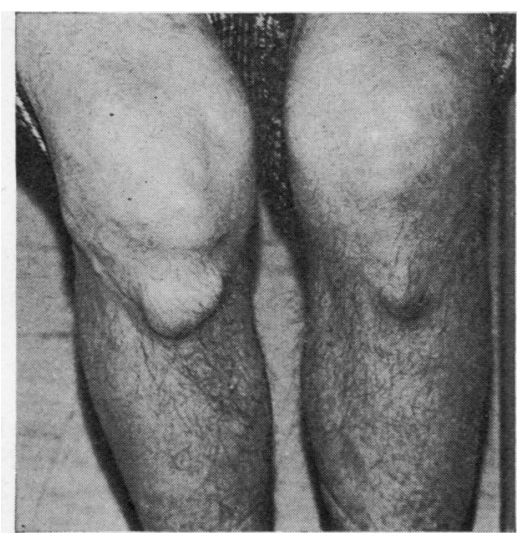

FIG. 2 Prepatellar tophaceous deposits, smaller on weakened left leg than on unaffected right leg

\section{INVESTIGATIONS}

There were tophaceous deposits on the dorsum of the proximal interphalangeal joints of the right index and middle fingers, and over the metacarpophalangeal joint of the right small finger. The deposits were becoming larger and more painful, and were limiting function (Fig. 1). There were no deposits in the left hand. Prepatellar deposits in the partially paralysed left leg were smaller than those on the right leg (Fig. 2). At operation, chalk-white deposits were removed from the subcutaneous and paratendinous areas of the right hand. Pathological examination of the specimens obtained at operation showed connective tissue containing masses of needle-like crystals with the refractive characteristics of urates.

\section{Discussion}

This patient's history suggests that hemiplegia has a protective effect on the development of chronic tophaceous gouty deposits. The sparing effect of hemiplegia on the development of Heberden's nodes in the unaffected extremities was noted by Coste and Forestier (1935). Thompson and Bywaters (1962) reported 4 patients with hemiplegia who subsequently developed rheumatoid arthritis. In each of these patients the destructive joint changes were more severe on the nonhemiplegic side. They concluded that disuse played a significant role in the protective effect of hemiplegia. Courtright and Kuzell (1964) reported on an elderly woman with advanced arthritis of the small joints of both hands; superimposed hypertrophic changes of rheumatoid arthritis occurred in all but one finger. This finger had no arthritis and the sparing was attributed to a flexor tendon laceration that had occurred 50 years before. Furthermore, in the rat they studied the effect of adjuvant arthritis on neural deficits produced by varied trauma, including the cutting of the sciatic nerve. A sparing effect on the development of adjuvant arthritis was recorded in both neurectomized and traumatized limbs. It seems likely that our patient, too, was spared from gout on the paralysed side by the disuse resulting from hemiplegia.

\section{References}

Coste, F., ANd Forestier, J. (1935) Bull. Soc. med. Hop. Paris, 51, 772 (Hémiplégie et nodosités d'Heberden controlatérales)

Courtright, L. J., AND Kuzell, W. C. (1965) Ann. rheum. Dis., 24, 360 (Sparing effect of neurological deficit and trauma on the course of adjuvant arthritis in the rat)

Thompson, M., AND Bywaters, E. G. L. (1962) Ibid., 21, 370 (Unilateral rheumatoid arthritis following hemiplegia) 